\title{
Efficacy versus Effectiveness
}

\section{Editorial}

\author{
Soo Young Kim
}

Department of Family Medicine, Kangdong Sacred Heart Hospital, Hallym University College of Medicine, Seoul, Korea

Archie Cochrane, British famous clinical epidemiologist, defined two concepts related to assessing healthcare interventions. Efficacy is the extent to which an intervention does more good than harm under ideal circumstances. Effectiveness assesses whether an intervention does more good than harm when provided under usual circumstances of healthcare practice. ${ }^{1)}$

Research on efficacy and effectiveness has also been described as explanatory and pragmatic trials. When defining the research question, it must be considered whether one asking a pragmatic or an explanatory question. This will have important implications for study design. ${ }^{2)}$ Pragmatic research assesses whether an intervention works under real-life conditions and whether it works in terms that matter to the patient. Explanatory research assesses whether an intervention works under ideal or selected conditions. The distinction between pragmatic and explanatory research is important because it will determine key methodological issues relating to patient selection, definition of the intervention and controls, use of blinding and placebos, choice of outcome measure, and type of analysis.

Efficacy studies are frequently conducted in large tertiary care, referral settings, which tend to have more specialized clinicians and better technical equipment than primary care facilities. For effectiveness trials, settings should reflect the initial care facilities available to a diverse population with the condition of interest. Therefore, populations in primary care may be an adequate subject group for effectiveness studies. ${ }^{4)}$

The Korean Journal of Family Medicine (KJFM) publishes research and reviews related to primary care, and those related to clinical and epidemiological health services. This means that the KJFM is focused primarily on the publication of effectiveness research. The distinctions between pragmatic and explanatory research pertain to patient selection, definition of the intervention and controls, and choice of outcome measure. Effectiveness research has several characteristics: 1) patient selection should reflect routine practice; 2 ) the intervention should be provided by normal staff with routine training; 3 ) the control may therefore be routine practice rather than a placebo; 4) outcome measures are usually patient centered and incorporate broad measures of health-related quality of life. ${ }^{5)}$ The editorial board, reviewer, and authors must all have such an understanding to achieve the aims and scope of the KJFM.

\section{CONFLICT OF INTEREST}

No potential conflict of interest relevant to this article was reported.

\section{REFERENCES}

1. Haynes B. Can it work? Does it work? Is it worth it? The testing of healthcare interventions is evolving. BMJ 1999;319: 652-3.

2. Roland M, Torgerson DJ. What are pragmatic trials? BMJ 1998;316:285.

3. The College of Emergency Medicine. Pragmatic versus explanatory trials [Internet]. London: The College of Emergency Medicine [cited 2013 Jun 29]. Available from: http://www.collemergencymed.ac.uk/CEM/Research/ technical_guide/pragex.htm.

4. Gartlehner G, Hansen RA, Nissman D, Lohr KN, Carey TS. A simple and valid tool distinguished efficacy from effectiveness studies. J Clin Epidemiol 2006;59:1040-8.

5. Thorpe KE, Zwarenstein M, Oxman AD, Treweek S, Furberg $\mathrm{CD}$, Altman DG, et al. A pragmatic-explanatory continuum indicator summary (PRECIS): a tool to help trial designers. J Clin Epidemiol 2009;62:464-75. 